\title{
Sintomas neurológicos transitórios associados à raquianestesia - relato de caso
}

\section{Transient neurological symptoms associated to spinal anesthesia - case report}

Maria Cecília Magalhães ${ }^{1}$. Josenília Maria Alves Gomes². Ana Virgínia Tomaz Portella². Liane Carvalho de Brito Souza ${ }^{2}$. Marcos Castelo Magalhães ${ }^{3}$.

1 Instituto Dr José Frota, Hospital Maternidade Dra Zilda Arns Neumam, Fortaleza, Ceará, Brasil. 2 Hospital Universitário Walter Cantídio (HUWC), Universidade Federal do Ceará (UFC), Fortaleza, Ceará, Brasil. 3 Universidade Federal do Ceará (UFC), Fortaleza, Ceará, Brasil.

\section{RESUMO}

Objetivos: apresentar um caso de sintomas neurológicos transitórios (SNT) de duração e apresentação pouco habitual em paciente submetida à apendicectomia sob raquianestesia. Relato de Caso: paciente feminina, 44 anos, submetida à raquianestesia para realização de apendicectomia. Referiu intensa sensação de choque no pé direito durante realização do bloqueio anestésico e evoluiu no pós-operatório imediato com quadro de dor, de moderada intensidade, de padrão neuropático em pé direito (dermátomo S1), além de disfunção esfincteriana. Realizou-se investigação com ressonância nuclear magnética de coluna lombar e eletroneuromiografia de membros inferiores, descartando-se etiologia infecciosa e vascular, sendo provável a causa de trauma durante a inserção da agulha de punção. O tratamento incluiu uso de antidepressivo tricíclico, corticoide e gabapentinoide com regressão completa da sintomatologia, porém lenta, num período de 3 meses. Conclusão: apesar do desfecho favorável na maioria dos casos de SNT, medidas de prevenção devem ser adotadas para evitar tal complicação neurológica, tais como técnica anestésica adequada, correto posicionamento na mesa cirúrgica, medidas para evitar hipotensão prolongada e isquemia neural.

Palavras-chave: Anestesia. Raquianestesia. Anestesia por condução.

\section{ABSTRACT}

Objectives: To report a case of transient neurologic symptoms (TNS) of uncommon duration and presentation in a patient submitted to appendectomy under spinal anesthesia. Case Report: A 44-year-old female patient submitted to appendectomy under spinal anesthesia reported intense sensation of electric shock during the spinal anesthesia blockade procedure. The patient presented pain of moderate intensity and right foot neuropathic pattern (S1 dermatome) during the postoperative period, besides sphincter dysfunction. An MRI of the lumber spine and an electroneuromyography discarded infectious or vascular etiologies for the patient's symptoms, which makes trauma during insertion of the puncture needle likely to be the cause of the symptoms. Treatment included the use of a tricyclic antidepressant, a corticosteroid and a gabapentinoid drug, with complete - but slow - remission of symptoms, over a three-month period. Conclusion: Though most cases of TNS have a positive outcome, preventive measures, such as adequate anesthesia techniques, correct positioning on the surgical table, measures to avoid prolonged hypotension and neural ischemia, must be adopted to avoid neurological complications.

Keywords: Anesthesia. Spinal anesthesia. Anesthesia, conduction.

Autor correspondente: Maria Cecília Magalhães, Rua Doutor José Lourenço, 1550, Aldeota, Fortaleza, Ceará. CEP: 60115-281. Telefone: +55 85 99719-0607. E-mail: cecimagalhaes83@gmail.com

Conflito de interesses: Não há qualquer conflito de interesses por parte de qualquer um dos autores.

Recebido em: 29 Mai 2018; Revisado em: 30 Jul 2018; Aceito em: 14 Set 2018. 


\section{INTRODUÇÃO}

O bloqueio subaracnoideo ou raquianestesia é uma das técnicas anestésicas mais difundidas em todo o mundo. Após mais de 100 anos de evolução e aprimoramento da técnica, com redução gradual de seus efeitos adversos, a raquianestesia conquistou grande popularidade. Trata-se de técnica muito explorada pela sua simples execução, eficácia e baixos custo e toxicidade. ${ }^{1}$

Apesar da segurança da técnica e baixa incidência de complicações graves, diversos efeitos adversos foram associados ao bloqueio subaracnoideo, dentre eles: cefaleia pós-punção, lombalgia, distúrbios de micção, complicações cardiovasculares, distúrbios de coagulação, meningites e complicações neurológicas. ${ }^{2}$

As complicações neurológicas são eventos infrequentes, mas que geram grande apreensão na equipe anestésica envolvida e têm como principais fatores etiológicos trauma ocasionado pela agulha de punção e a neurotoxicidade do anestésico local. ${ }^{3}$

O objetivo deste artigo é apresentar um caso de complicação neurológica, caracterizado por sintomas neurológicos transitórios (SNT) de duração pouco habitual, em paciente submetida à raquianestesia para apendicectomia.

\section{RELATO DE CASO}

Paciente de 44 anos, branca, casada, fisioterapeuta. Tinha antecedente mórbido de doença reumatológica a esclarecer, caracterizada por poliartrite, sacroileíte bilateral e alteração de FAN (fator anti-nuclear), Fator Reumatóide e anticardiolipina. Relato de episódio de trombose venosa profunda no passado, distrofia de córnea e duplicidade pielo-calicial. Foi atendida no Ambulatório de Dor do Núcleo de Atenção Médica Integrada (NAMI), 52 dias após ter sido submetida à apendicectomia sob raquianestesia em hospital privado de Fortaleza. Na ocasião, após adequada anti-sepsia toracolombar, realizou-se punção subaracnoidea mediana com agulha de Quincke 26G ao nível do espaço L2-L3. Durante a introdução da agulha, paciente referiu forte sensação de choque nos membros inferiores, principalmente no membro inferior direito. Após refluxo de líquor límpido, a solução anestésica foi injetada, sem queixas álgicas. Foram utilizados $4 \mathrm{ml}$ de Bupivacaína hiperbárica $0,5 \%$ e $80 \mathrm{mcg}$ de Morfina, totalizando 4,4 $\mathrm{ml}$ de solução. O procedimento cirúrgico transcorreu sem maiores intercorrências. No pós-operatório imediato, após recuperação da anestesia, a paciente evoluiu com episódios de urgência urinária e fecal, parestesias e dor em choque no pé direito (dermátomo S1), além de câimbras aos movimentos de dorsiflexão e extensão plantar do mesmo pé. Vinha em uso de Etna ${ }^{\circledR} 3$ vezes ao dia, amitriptilina $12,5 \mathrm{mg} /$ noite e prednisona $60 \mathrm{mg} /$ dia desde a alta hospitalar. Relatou melhora da sintomatologia com o início do tratamento, apresentando redução progressiva dos episódios de urgência urinária e fecal, porém, ainda com queixas de dor tipo choque com Escala Verbal Numérica $(E V N)=7$ e parestesias no pé direito. Foi realizado exame neurológico sensitivo e motor dos membros inferiores que foi normal. A eletroneuromiografia dos membros inferiores também não evidenciou anormalidades e a ressonância nuclear magnética de coluna lombar mostrou abaulamento discal difuso em L4-L5, sem sinais de compressão radicular, abscessos ou hematomas. Optamos por manter as medicações prescritas e associar pregabalina $75 \mathrm{mg} /$ noite. Na consulta seguinte, 80 dias após o procedimento anestésico-cirúrgico, a paciente retornou referindo melhora do quadro álgico $(\mathrm{EVN}=3)$, com choques ocasionais no pé direito no dermátomo $\mathrm{S} 1$ e redução da intensidade e frequência das câimbras, sem queixas esfincterianas. Foi suspenso Etna ${ }^{\circledR}$ e mantida a prescrição de amitriptilina $12,5 \mathrm{mg} /$ noite e pregabalina $75 \mathrm{mg} /$ noite. Houve melhora progressiva dos sintomas, com completa recuperação, cerca de 4 meses após o procedimento.

\section{DISCUSSÃO}

Sintomas neurológicos transitórios (SNT) foram descritos por Schneider e col em $1993^{4}$ e caracterizados inicialmente como um quadro de dor nas costas, que irradia-se para nádegas e face dorsolateral das pernas, podendo ser acompanhada por disestesias. Geralmente restrita aos dermátomos L5$\mathrm{S} 1$, esta dor inicia-se nas primeiras horas que seguem a regressão da anestesia subaracnoidea, sempre após um período livre de sintomas. A dor, na maioria dos casos, é de moderada intensidade, com duração média de 2 a 3 dias. Os reflexos músculo-tendinosos e as funções vesical e intestinal costumam estar preservados. Amplo estudo prospectivo sobre complicações em mais de 100.000 casos de anestesias regionais, encontrou uma incidência de $0,04 \%$ de SNT após raquianestesia e 0,01\% após anestesia peridural. ${ }^{5}$ Lesão neurológica permanente, caracterizada por persistência dos sintomas após 3 meses, também é evento extremamente raro. Sua incidência é de $0,07 \%$ nas anestesias espinhais, sendo de $0,1 \%$ após anestesia peridural e $0,03 \%$ após anestesia subaracnoidea. ${ }^{6}$

O tipo de anestésico utilizado no bloqueio parece interferir na incidência de SNT, bem como a posição que o paciente permanece durante o procedimento cirúrgico. SNT tipicamente ocorrem após anestesia subaracnoidea em que foi usada lidocaína, sendo este anestésico considerado fator predisponente para a complicação. A incidência de SNT varia de 10-37\% com uso de lidocaína hiperbárica a 5\%, 0 a 3\% com bupivacaína, 30 a $37 \%$ com mepivacaína e $6,8 \%$ com tetracaína. ${ }^{7}$ Pacientes que permanecem em posição de litotomia no intra-operatório tem incidência de SNT de 30 a $36 \%,{ }^{8}$ enquanto que pacientes que permanecem com o joelho flexionado para realização de artroscopia apresentam incidência entre 18 e $22 \%$ e pacientes em posição supina, entre 4 e $8 \%{ }^{8}$

Dentre os possíveis fatores etiológicos envolvidos no aparecimento de SNT, podemos citar: trauma da medula espinhal ou raízes nervosas provocado pela agulha de punção ou cateter, toxicidade do anestésico local, isquemia neural, infecções e má-distribuição do anestésico local. 
As lesões originárias do trauma desencadeado pela agulha de punção ou pelo cateter raramente resultam em lesões neurológicas permanentes ou incapacitantes. Sempre que a agulha de punção se afasta da linha média, seja intencionalmente (punções paramedianas), seja acidentalmente, existe o risco de trauma da raiz nervosa. Estruturas vasculares também localizam-se lateralmente à medula e lesões nestes vasos podem causar hematomas ou interromper o fluxo sanguíneo para a região. ${ }^{3}$ Punções realizadas acima de L3 e o uso de agulhas em ponta de lápis, quando é necessário introduzir a agulha numa maior extensão para obtenção de líquor, também podem resultar em trauma medular direto ou das raízes que constituem a cauda equina. É sempre recomendável que, ao se puncionar o espaço subaracnóideo, não se faça progressão demasiada da agulha. Após sentir a perfuração da dura-máter e aracnoide, deve ser observado o gotejamento de líquor, cuja presença é suficiente para injetar a solução em local adequado, minimizando o risco de lesão neural. A parestesia unilateral em território de um dermátomo é indicador clássico de introdução da agulha proximalmente ao nervo, e a sua ocorrência durante a realização do bloqueio pode representar fator de risco para o surgimento de SNT. Auroy e col observaram em seu estudo que $2 \backslash 3$ dos pacientes com complicações neurológicas queixaram-se de dor durante a introdução da agulha ou injeção do anestésico local..$^{5}$ A passagem ou presença de um cateter constitui fonte adicional de trauma, podendo dobrar a incidência de parestesias em técnicas contínuas quando comparadas às técnicas por punção única. ${ }^{9}$ Para se evitar a lesão por agulha e cateter, recomenda-se que a punção lombar seja efetuada abaixo de L3, visto que em até $60 \%$ dos adultos a medula termina no nível da vértebra L1, em $30 \%$ termina no nível da vértebra T12 e em 10\% dos casos no nível da vértebra L3. Os bloqueios devem ser realizados preferencialmente com pacientes acordados ou sob leve sedação, para que possam relatar a ocorrência de sintomas, como dor e parestesias, durante a realização do mesmo. ${ }^{10}$

Em relação à neurotoxicidade direta dos anestésicos locais, estudos laboratoriais comprovaram a sua ocorrência, não permitindo descartá-la como fator causal dos SNT. No entanto, diferentemente do que ocorre na síndrome da cauda equina, SNT foram observados na vigência do uso de lidocaína em concentrações tão baixas quanto $0,5 \%$, de modo que altas concentrações de anestésicos locais não parecem ser importantes para determinar sua ocorrência. Em estudo com o objetivo de determinar se os SNT eram resultado de neurotoxicidade direta da lidocaína, pacientes que apresentaram esses sintomas foram avaliados com auxílio de eletroneuromiografia, estudos de condução nervosa e potenciais evocados somato-sensoriais e não foram observadas quaisquer alterações eletrofisiológicas nesses pacientes, não corroborando a hipótese de toxicidade direta. ${ }^{11}$ Atualmente acredita-se que a lidocaína, por determinar maior relaxamento muscular, propicia estiramento musculoesquelético e dor quando o paciente permanece em posição de litotomia. ${ }^{3}$

Um outro possível fator etiológico é a isquemia da medula espinhal e das raízes nervosas, a qual pode ocorrer em situações de hipotensão prolongada ou uso de vasoconstritores. O estiramento de raízes lombares e sacrais secundário ao relaxamento muscular do bloqueio e ao posicionamento cirúrgico também poderia provocar uma redução do fluxo sanguíneo local, gerando isquemia e favorecendo a ação tóxica dos anestésicos, mesmo em baixas concentrações. ${ }^{3}$

Sabe-se que a baricidade e a osmolaridade da solução, a adição de vasoconstritor e a concentração do anestésico local não são fatores determinantes para o aparecimento de SNT, ${ }^{12}$ assim como o tipo e calibre da agulha.

Neste relato de caso, a paciente referiu intensa parestesia em membros inferiores durante a realização do bloqueio. Além disso, a punção foi realizada ao nível L2-L3, considerado espaço de exceção para realização do bloqueio. Os espaços L3-L4 e L4-L5 são os mais seguros no tocante à localização do cone medular e densidade de raízes nervosas. Essas observações sugerem lesão traumática de alguma raiz nervosa ou do próprio cone medular como principal causa da complicação apresentada. Embora o desfecho clínico seja favorável na maioria dos casos de SNT, é de grande importância que as orientações técnicas sejam rigorosamente seguidas para prevenir tal complicação. $\mathrm{Na}$ ocorrência de parestesias durante a punção, é imperioso retroceder a agulha e reposicioná-la, ou mesmo que seja realizada nova punção em diferente espaço, e que nenhuma injeção de anestésico ocorra na vigência de dor ou parestesias. Atenção especial deve ser dada ao posicionamento cirúrgico, especialmente quando se utiliza posição de litotomia e frog leg, bem como à escolha criteriosa e identificação do espaço intervertebral mais seguro para realização da punção.

O tratamento desta complicação costuma ser feito com medicamentos sintomáticos, como analgésicos comuns e adjuvantes para o controle da dor, além de medidas fisioterápicas nos casos persistentes e de déficit motor e/ou esfincteriano. Antidepressivos tricíclicos, duais e gabapentinoides estão entre os adjuvantes de escolha para tratamento da dor neuropática. O uso de corticoides em altas doses na fase aguda do trauma espinhal (primeiras 8 horas) diminui significativamente o déficit neurológico. $\mathrm{O}$ benefício desses agentes ainda não foi estabelecido em lesões secundárias à anestesia espinhal. ${ }^{13}$

No caso apresentado, houve recuperação mais lenta que o habitual quando se compara à evolução típica de SNT. No entanto, a recuperação completa, dentro de um período de aproximadamente 3 meses, sem qualquer sequela neurológica, bem como exames de imagem e eletroneuromiografia de membros inferiores normais, reforçam esse diagnóstico.

\section{CONCLUSÃO}

Apesar do desfecho favorável na maioria dos casos de SNT, medidas de prevenção devem ser adotadas para evitar tal complicação neurológica, tais como técnica anestésica adequada, correto posicionamento na mesa cirúrgica, medidas para evitar hipotensão prolongada e isquemia neural, proporcionando ao paciente plena e rápida recuperação anestésico-cirúrgica. 


\section{REFERÊNCIAS}

1. Cangiani LM, Cangiani LH, Lutti MN, Esteves LO. Anestesia subaracnóidea. In: Cangiani LM, Slullitel A, Potério GM, Pires OC, Posso IP, Nogueira CS, et al. Tratado de anestesiologia. 7. ed. São Paulo: Editora Atheneu; 2011. p. 1479-1514.

2. Rocha RO, Teixeira MJ, Yeng LT. Lesão neurológica transitória associada à anestesia subaracnóidea: relato de caso. Rev Dor. 2009;10(1):74-7.

3. Ganem EM, Castiglia YM, Vianna PT. Complicações neurológicas determinadas pela anestesia subaracnóidea. Rev Bras Anestesiol. 2002;52(4):471-80.

4. Schneider M, Ettlin T, Kaufmann M, Schumacher P, Urwyler A, Hampl K, et al. Transient neurologic toxicity after hyperbaric subarachnoid anesthesia with $5 \%$ lidocaine. Anesth Analg. 1993;76(5):1154-7.

5. Auroy Y, Narchi P, Messiah A, Litt L, Rouvier B. Samii K. Serious complications related to regional anesthesia: results of a prospective survey in France. Anesthesiology. 1997;87(3):479-86.

6. Dahlgren N, Tornebrandt K. Neurological complications after anaesthesia. A follow-up of 18000 spinal and epidural anaesthetics performed over three years. Acta Anaesthesiol Scand. 1995;39(7):872-80.
7. Faccenda KA, Finucane BT. Complications of regional anaesthesia: incidence and prevention. Drug Saf. 2001;24(6):413-42.

8. Ganem EM. Bloqueio do neuroeixo-fatores que interferem no desfecho pós-operatório. In: Cavalcanti IL, Cantinho FA, Assad A. Medicina perioperatória. Rio de Janeiro: Sociedade de Anestesiologia do Estado do Rio de Janeiro; 2006. p. 1071-7.

9. Gentili F, Hudson AR, Hunter D, Kline DG. Nerve injection injury with local anesthetic agents: a light and electron microscopic, fluorescent microscopic and horseradish peroxidase study. Neurosurgery. 1980;6(3):263-72.

10. Wong CA. Neurologic deficits and labor analgesia. Reg Anesth Pain Med 2004;29:341-51.

11. Pollock JE, Burkhead D, Neal D. Spinal nerve function in five volunteers experiencing transient neurologic symptoms after lidocaine subarachnoid anesthesia. Anesth Analg. 2000;90:658-65.

12. Pollock JE, Neal JM, Stephenson CA, Willey CE. Prospective study of the incidence of transient radicular irritation in patients undergoing spinal anesthesia. Anesthesiology. 1996;84(6):1361-7.

13. Mendes FM, Luft A, Gomes LC. Déficit neurológico após bloqueio espinhal: relato de caso. Rev Bras Anestesiol. 1999; 49(1):38-9.

\section{Como citar:}

Magalhães MC, Gomes JM, Portella AV, Souza LC, Magalhães MC. Sintomas neurológicos transitórios associados à raquianestesia - relato de caso. Rev Med UFC. 2019 abr-jun;59(2):54-57. 